\title{
Effective Use of Genomics in Commercial Dairy Farms ${ }^{1}$
}

\author{
Francisco Peñagaricano ${ }^{2}$
}

\section{Introduction}

Genomic selection refers to selection decisions based on genomic-estimated breeding values. These genomic breeding values are calculated using genetic markers across the entire genome. This technology has revolutionized dairy cattle breeding globally. Genomic selection has the potential to increase genetic gain considerably by reducing generation intervals and increasing selection intensity and accuracy. Using genomics can approximately double the rate of genetic progress for economically important traits (Wiggans et al. 2017; Garcia-Ruiz et al. 2016). Thousands of animals are genotyped every year, and this genomic information is fully integrated into national genetic evaluations. Pedigree breeders use genomic testing to identify the most elite males and females in the populations, and those animals become the sires and dams of the next generation of young bulls. Genomic selection also offers great benefits for commercial producers (Pryce and Hayes 2012; Schefers and Weigel 2012). This publication assesses the potential value of genomics to commercial dairy farmers.

\section{Effective Use of Genomics: Sire Selection}

Progeny testing has been the basis of genetic selection programs in dairy cattle breeding. It has led to remarkable genetic gains in production traits. For example, predicted transmitting ability (PTA) values of US Holstein bulls have increased by $81 \mathrm{lb}$. of milk per year over the last three decades. However, progeny testing is a time-consuming process. At least 4.5 years are required to collect semen of a potential elite bull, rear his offspring, and finally predict his genetic merit based on his offspring's performance. If we decide that the bull is good enough to use in the entire population, then his first sons and daughters will be born when he is about 5.5 years of age. This long generation interval limits the rate of genetic progress. In this context, the use of genomic testing, namely the use of genetic markers across the genome to predict breeding values, allows us to identify and select animals at an early age. This drastic reduction in the generation interval has a positive impact on the rate of genetic gain.

Dairy sire selection has dramatically changed with the arrival of genomics. Dairy farmers now have two main options when they make sire selection decisions: use proven (progeny-tested) bulls or use young genomic-tested bulls (i.e., young bulls with no progeny that have been evaluated using only their own genomic data). The National Association of Animal Breeders (NAAB) classifies these two groups of bulls as the active (A) bulls, progeny-tested bulls with performance information in at least 10 daughters, and the young genomic-tested (G) bulls, young bulls that have not yet produced milk-recorded offspring. It is important to note that the number of young genomic-tested bulls currently in the market far exceeds that of progeny-tested bulls. For instance, of the 2,741 Holstein bulls available in the market in August 2016, 2,172 (79\%) were young genomic-tested bulls. Similarly, 403 of the 534 available Jersey bulls had G status.

1. This document is AN340, one of a series of the Department of Animal Sciences, UF/IFAS Extension. Original publication date February 2018. Visit the EDIS website at http://edis.ifas.ufl.edu.

2. Francisco Peñagaricano, assistant professor, Department of Animal Sciences; UF/IFAS Extension, Gainesville, FL 32611.

The Institute of Food and Agricultural Sciences (IFAS) is an Equal Opportunity Institution authorized to provide research, educational information and other services only to individuals and institutions that function with non-discrimination with respect to race, creed, color, religion, age, disability, sex, sexual orientation, marital status, national origin, political opinions or affiliations. For more information on obtaining other UF/IFAS Extension publications, contact your county's UF/IFAS Extension office. 
On average, these young genomic-tested dairy bulls have greater predicted genetic merit values than the proven bulls. Figure 1 shows the average PTA value for lifetime net merit (NM\$) for the group of active (A) and genomic-tested (G) Holstein and Jersey bulls marketed to US dairy farmers in August 2016. The net merit of young genomic-tested bulls is $\$ 270$ and $\$ 124$ greater than that of progeny-tested bulls in Holstein and Jersey breeds, respectively. Notably, if we rank the A and G bulls based on PTA NM\$ values and then consider only the top 100 , we find that $98 \%$ and $87 \%$ of these elite Holstein and Jersey bulls, respectively, are young genomic-tested bulls. If we consider that the changes achieved through genetic selection are cumulative and permanent, then it is expected that the new generations ( $G$ bulls) will, on average, have greater genetic merit than the older generations (A bulls). Now, in the case of the young genomic-tested dairy bulls, higher genetic values are accompanied by lower reliability values. The reliability of PTA NM\$ values of young bulls is $26 \%$ and $19 \%$ lower than for proven bulls in Holstein and Jersey breeds, respectively (Figure 1). This is not surprising considering that the young genomic-tested bulls do not have progeny yet.

The question remains if we should use young genomictested bulls because they have greater PTA values, or proven bulls because they have more reliable PTA estimates. At this point, it is important to note that sire selection decisions should be always based on PTA values. As such, we should not select or exclude sires based only on reliability; rather, we should use the value of reliability as a guide to decide how intensely we want to use a bull. Therefore, when we consider the dilemma of young genomic-tested vs. proven dairy bulls, the best strategy is to use a group or team of young genomic-tested bulls. Table 1 shows how the reliability of the genetic merit of the team (calculated simply as the average genetic merit) increases as we include more young bulls in the team. For instance, if the REL values of individual young genomic-tested bulls is $70 \%$, then REL of the average genetic merit for a team of three young bulls is about $90 \%$. If we increase the group size to six or even 12 young bulls, we achieve REL values for the group average between $95 \%$ and $98 \%$.

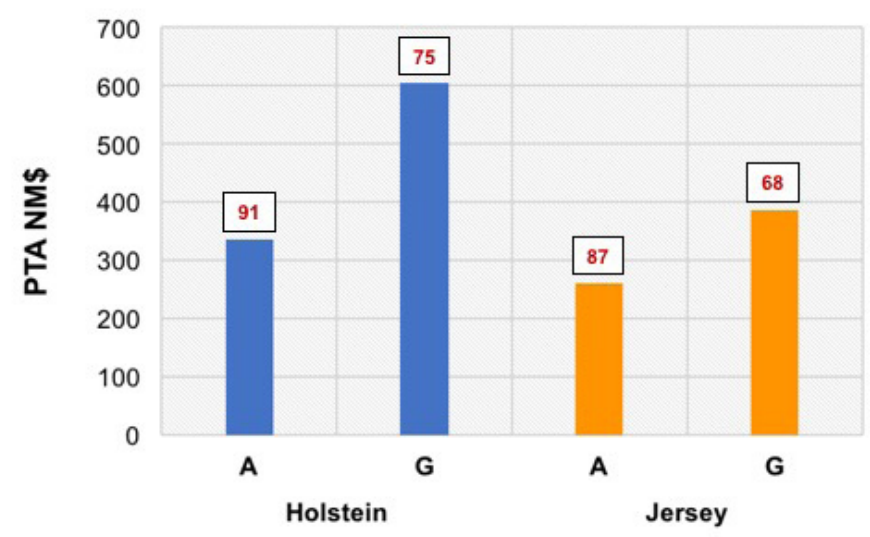

Figure 1. Average predicted transmitting ability (PTA) values (in the $y$-axis) and the corresponding reliability (REL) values (above the bars) for Lifetime Net Merit (NM\$) for active (A) and genomic-tested (G) Holstein and Jersey bulls marketed to US dairy farmers. Credits: Based on the August 2016 Council on Dairy Cattle Breeding (CDCB) genetic evaluations (https://www.uscdcb.com).

Table 1. Change in the reliability of the group genetic merit (calculated as the average genetic merit of the group) as a function of the number of young genomic-tested bulls in the group.

\begin{tabular}{|c|c|}
\hline $\begin{array}{c}\text { Number of Genomic-Tested } \\
\text { Bulls in the Group }\end{array}$ & $\begin{array}{c}\text { Reliability of the Group } \\
\text { Genetic Merit }\end{array}$ \\
\hline 1 & 70 \\
\hline 3 & 90 \\
\hline 6 & 95 \\
\hline 12 & 98 \\
\hline
\end{tabular}

\section{Effective Use of Genomics: Replacement Heifer Selection}

The selection of replacement heifers in commercial dairy farms has been traditionally characterized by low selection intensity, because farmers generally retain nearly every heifer calf as a future herd replacement. However, recent improvements in herd management have reduced involuntary culling rates and improved reproductive efficiency, which have led to the ability to produce excess heifers. The use of sexed semen can also generate a surplus of heifer calves. In this context, the selection of replacement heifers is feasible. The key question here is: how do we select the necessary replacements? In other words, how can we identify superior or inferior heifer calves accurately? The use of genomic testing allows us to identify and select heifers at an early age.

What are the advantages of using genomics for heifer calf selection? In the absence of genomic information, the selection or culling of a given heifer calf is based on the average genetic merit of her parents. The reliability of this information typically ranges from 0 when we do not know the parents to 0.40 if we have access to complete pedigree 
information. If we use genomic testing, then the reliability of the genomic-predicted genetic merit of the heifer calf ranges from 0.55 to 0.75 depending on the trait of interest and the amount of pedigree data available. Interestingly, this genomic prediction early in life is generally more reliable than the traditional PTA estimated using several lactation records on both the cow and her daughters. Therefore, genomic testing allows us to make accurate selection (culling) decisions at an early age that are more reliable than those based on pedigree information alone.

Recently, colleagues at the University of Wisconsin-Madison compared early genomic predictions with subsequent production and reproduction performance in the first lactation of Holstein cows (Figure 2) (Weigel, Mikshowsky, and Cabrera 2015). Cows were ranked based on their own genomic PTA values (predicted at 12 months of age). These alternative quartile rankings (from top 25\% to bottom 25\%) were compared with the actual phenotypic performance in first lactation. If there is an association between genomic testing and future performance, then we would expect the best heifers in terms of genomic values to show greater phenotypic records. For milk production, the observed difference between the top and the bottom quartiles was equal to $4,800 \mathrm{lb}$. For female fertility, the actual difference in days open between those heifers classified as top $25 \%$ and those classified as bottom $25 \%$ was equal to 21 days. These findings suggest that early genomic predictions (performed on calves or yearling heifers) can be effectively used as predictors of future performance. In other words, genomic testing can be used to make accurate selection decisions at a young age.

Genomic information on individual animals can be used to reduce feed costs and improve the genetic level of herd replacements. The identification of genetically inferior heifer calves allows early culling of these animals, significantly reducing the cost of rearing replacements. Alternatively, these genetically inferior heifers can be inseminated with beef semen to produce high-value crossbred beef calves. Note that these inseminated cows are removed as parents of the next generation. On the other hand, the identification of superior heifers through genomics can be combined with the use of advanced reproductive technologies to rapidly propagate these animals and generate superior replacements. For instance, high-genetic-merit heifers can be used as donors in either an in-vitro fertilization program or an embryo transfer program. These superior heifers can be inseminated using sexed semen from top sires.

It is worth noting that genotyping replacement heifers has additional benefits, including verifying parentage, controlling inbreeding, and avoiding the spread of genetic disorders by using genomic-enhanced matings. Arguably, these benefits add value to genomic testing.
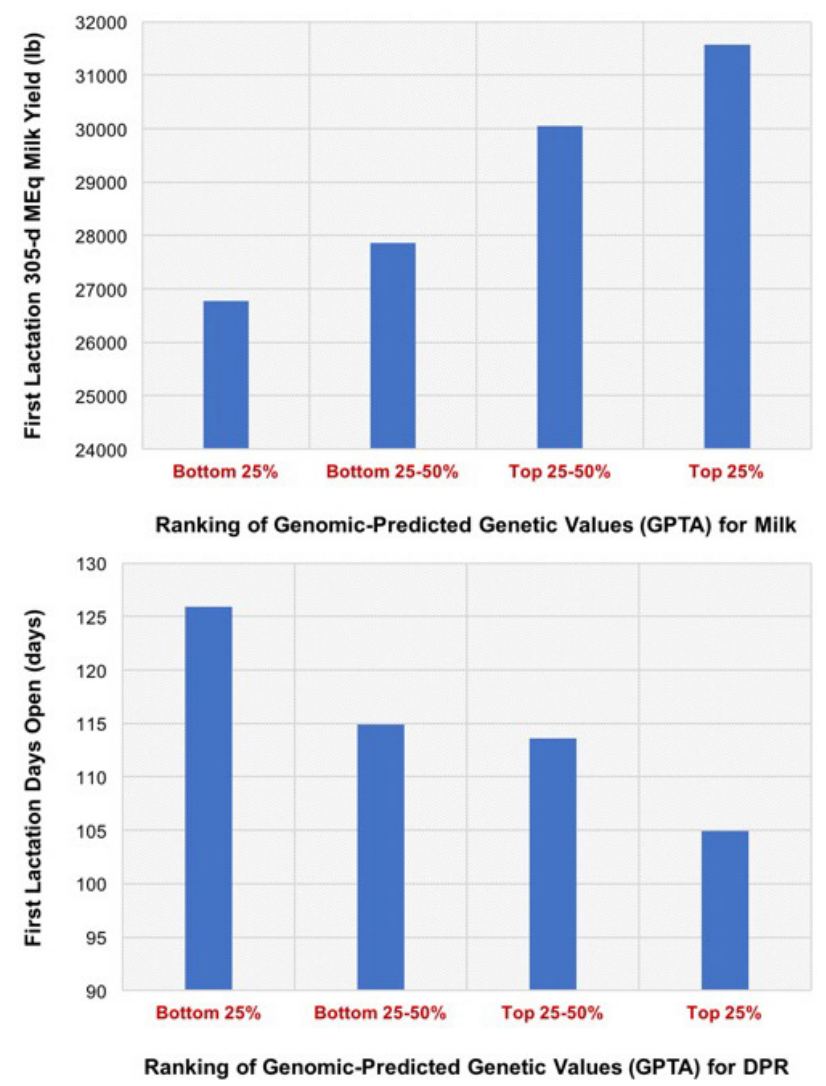

Figure 2. Production (305-d mature-equivalent (MEq) milk yield) and reproductive performance (days open) in first lactation according to the ranking of genomic values. The rankings were calculated based on genomic PTA values estimated at 12 months of age.

Credits: Adapted from Weigel, Mikshowsky, and Cabrera (2015).

\section{Conclusion}

Genomics has revolutionized dairy cattle breeding. Nowadays, young genomic-tested bulls represent the vast majority of semen available on the market. On average, these genomic-tested bulls have greater genetic merit than proven bulls. Therefore, commercial dairy farmers now have a unique opportunity to harness the benefits of genomics by selecting superior young genomic-tested bulls. These young bulls have reliability values of approximately $70 \%$, so farmers should manage the risk associated with imprecision in PTA estimates by using a group of young bulls instead of focusing too heavily on individual animals. Moreover, dairy farmers can use genomic testing to support more accurate selection or culling replacement decisions. Those producers that combine genomic testing with other management decisions, such as early culling to reduce feed cost or the use of advanced reproductive technologies to rapidly propagate the best females in the herd, will reap the greatest benefits of this technology. 


\section{References}

Garcia-Ruiz, A., J. B. Cole, P. M. VanRaden, G. R. Wiggans, F. J. Ruiz-López, and C. P. Van Tassell. 2016. "Changes in genetic selection differentials and generation intervals in US Holstein dairy cattle as a result of genomic selection." Proc. Natl. Acad. Sci. USA 113: E3995-4004.

Pryce, J. and B. Hayes. 2012. "A review of how dairy farmers can use and profit from genomic technologies." Animal Production Science 52: 180-184.

Schefers, J. M. and K. A. Weigel. 2012. "Genomic selection in dairy cattle: Integration of DNA testing into breeding programs." Animal Frontiers 2: 4-9.

Weigel, K. A., A. A. Mikshowsky, and V. C. Cabrera. 2015, March. "Effective use of genomics in sire selection and replacement heifer management." Proceedings of the Western Dairy Management Conference. Reno, Nevada.

Wiggans, G. R., J. B. Cole, S. M. Hubbard, and T. S. Sonstegard. 2017. "Genomic selection in dairy cattle: the USDA experience." Annu. Rev. Anim. Biosci. 5: 309-327 